\title{
ZONEAMENTO AGROCLIMÁTICO DA CULTURA DA VIDEIRA PARA A ILHA DA MADEIRA - PORTUGAL
}

\author{
Fabrício Lopes de Macedo \\ Universidade da Madeira, ISOPlexis - Centro de Agricultura Sustentável e Tecnologia Alimentar, Funchal, \\ Portugal \\ fabriciolmacedo@hotmail.com \\ Carla Ragonezi \\ Universidade da Madeira, ISOPlexis - Centro de Agricultura Sustentável e Tecnologia Alimentar, Funchal, \\ Portugal \\ carla.ragonezi@staff.uma.pt
}

Miguel Ângelo Almeida Pinheiro de Carvalho

Universidade da Madeira, ISOPlexis - Centro de Agricultura Sustentável e Tecnologia Alimentar, Funchal,

\begin{abstract}
RESUMO
A cultura da vinha possuiu uma elevada importância na produção de vinhos de qualidade na llha da Madeira. No entanto para que a produção da cultura venha a produzir de maneira mais satisfatória é extremamente necessário o conhecimento dos locais mais propícios para o desenvolvimento da cultura. O objetivo do presente trabalho foi realizar um Zoneamento Agroclimático para a cultura da videira na llha da Madeira, visando fornecer dados para a tomada de decisão de produtores e técnicos na seleção de novos locais para implementação da cultura. Para tanto, foram utilizados dados de 11 estações meteorológicas convencionais localizadas em toda a llha da Madeira com períodos de observação de 1961 a 1990. A obtenção do deficit hídrico foi obtida por meio do balanço hídrico proposto por Thornthwaite \& Mather. Para o cultivo da videira na llha da Madeira, todo litoral Sul da Ilha, assim como boa parte do Norte, são áreas propicias para o desenvolvimento da cultura; no entanto no litoral sul, irrigação complementar é necessária para satisfazer as necessidades hídricas da cultura. Já no litoral Norte é necessário ter alguns cuidados com possível aparecimento de doenças fúngicas, devido aos grandes volumes de precipitação presentes na área.
\end{abstract}

Palavras-chave: Geotecnologia. Agricultura. Balanço Hídrico.

\section{AGROCLIMATIC ZONING FOR GRAPEVINE CULTIVATION FOR MADEIRA ISLAND - PORTUGAL}

\begin{abstract}
The cultivation of the vineyard has a high importance in the production of quality wines in Madeira Island. However for the production of the crop to produce in a more satisfactory way it is extremely necessary the knowledge of the most favorable places for the development of the culture. The objective of the present work was to carry out an Agroclimatic Zoning for the grapevine culture in the Island of Madeira, aiming to provide data for the decision making of producers and technicians in the selection of new places for implementation of the crop. For this purpose, data from 11 conventional meteorological stations located throughout the Island of Madeira were used with observation periods from 1961 to 1990 . The water deficit was obtained through the water balance proposed by Thornthwaite \& Mather. For the cultivation of grapevines on Madeira Island, all the southern coast of the Island, as well as much of the North, are areas conducive to the development of culture; however on the southern coast, additional irrigation is necessary to meet the water needs of the crop. In the North coast, it is necessary to have some care with possible appearance of fungal diseases, due to the large volumes of precipitation present in the area.
\end{abstract}

Keywords: Geotechnology. Agriculture. Water Balance.

$\begin{array}{lllll}\text { Caminhos de Geografia } & \text { Uberlândia } & \text { v. 21, n. 73 } & \text { Mar/2020 } & \text { p. 296-306 }\end{array}$ Página 296




\section{INTRODUÇÃO}

A atividade agrícola na llha da Madeira tem se desenvolvido mesmo com tantos obstáculos oriundos pela própria natureza. De acordo com Silva (2013) a ilha da Madeira encontra-se "confinada" entre o mar e a montanha, em que, encontram-se vales profundos entre os picos elevados (superior a 1800 $\mathrm{m})$. Para que a agricultura torne-se possível, as propriedades foram divididas em pequenas parcelas, e a população local recorreu à formação de socalcos (Terraços), chamados localmente de "poios".

O relevo montanhoso associado com as condições climáticas possibilitam uma grande variedade de cultivos agrícolas como por exemplo a bananeira, a cana-de-açúcar, o abacateiro, diversos frutos exóticos além de uma grande variedade de produtos hortícolas. Da área total de 7.137,96 ha, 5.262,2 ha é classificada como Superfície Agrícola Utilizada (SAU) (D.R.E.M, 2015). Dentre as culturas agrícolas produzidas na llha, a cultura da videira merece um grande destaque, graças à fabricação do Vinho Madeira, muito valorizado no comércio local e internacional.

Com relação as áreas que continham vinhas D.R.E.M (2015) salientam que apenas 1131,20 ha, eram as áreas ocupadas pela cultura. Ainda segundo os autores as principais áreas agrícolas localizam-se de maneira especial nas costas Sul e Este, graças as condições climáticas mais favoráveis (temperaturas mais elevadas) para o desenvolvimento das culturas, porém maior parte das culturas são produzidas com sistema de irrigação, devido aos baixos volumes de precipitação que ocorrem nas cotas mais baixas da llha.

Segundo Medeiros et al. (2013) o processo de delimitação climática de determinada localidade possibilita não apenas identificar os indicadores do meio físico, mas ainda, permite conhecer áreas homogêneas sob o ponto de vista socioeconômico, contribuindo para o planejamento e crescimento de atividades sustentáveis. O planejamento e zoneamento agrícola são uma das principais ferramentas para se prever os riscos e perdas na agricultura, logo, o entendimento e o conhecimento da dinâmica do clima são essenciais, visto que, as condições climáticas podem determinar a qualidade e o rendimento de uma cultura (MORAES, 2015).

Alguns dados são essenciais no processo de zoneamento climático como por exemplo a precipitação, a temperatura do ar, e a elaboração do balanco hídrico climatológico (BHC). Esse BHC consiste em um procedimento metodológico que regista a entrada e saída de água de um sistema, originando uma expressão quantitativa do clima hidrológico. A videira é uma cultura perene e muito sensível à ação climática (TONIETTO et al., 2012).

Diferentes efeitos são exercidos pela temperatura do ar, sendo que esses efeitos variam de acordo com as fases do ciclo vegetativo ou do período de repouso da planta (RICCE et al., 2014). A análise da cultura da vinha a uma escala global levou Jones (2007) a afirmar que, os limites que determinam a aptidão climática da cultura da videira localizam-se entre 12 e $22^{\circ} \mathrm{C}$ para o ciclo vegetativo.

Soares e Costa (2009) consideram que a videira tem um consumo hídrico localizado entre 450 a 900 $\mathrm{mm}$. Ricce et al. (2014) relatam que o excesso de precipitação pode ocasionar uma diminuição da qualidade dos frutos e consequentemente favorecer o aparecimento de doenças quando houver associação de temperatura e humidade elevadas. $O$ presente estudo tem por objetivo realizar o Zoneamento Agroclimático da videira para a llha da Madeira - Portugal, visando fornecer dados para a tomada de decisão de produtores e técnicos na seleção de novos locais para implementação da cultura.

\section{METODOLOGIA}

O arquipélago da Madeira localiza-se na região subtropical do Oceano Atlântico, na sub-região biogeográfica da Macaronésia, associada com os arquipélagos dos Açores, Selvagens, Canárias, Cabo Verde e uma parte da costa noroeste da África. O arquipélago é constituído por duas ilhas principais habitadas, a Madeira $\left(742 \mathrm{~km}^{2}\right)$ e o Porto Santo $\left(43 \mathrm{~km}^{2}\right)$ (Figura 1).

Segundo Cruz et al. (2009) a ilha possui 2 tipos de clima: mediterrânico e temperado. Ainda segundo os autores as temperaturas médias anuais situam-se na faixa dos 18 e $19^{\circ} \mathrm{C}$ nas zonas costeiras, porém, nos pontos mais altos da ilha a temperatura diminui para a faixa dos $9^{\circ}$.

\begin{tabular}{lllll}
\hline Caminhos de Geografia & Uberlândia & v. 21, n. 73 & Mar/2020 & p. 296-306 Página 297
\end{tabular}


Figura 1 - Ilha da Madeira e seus concelhos.

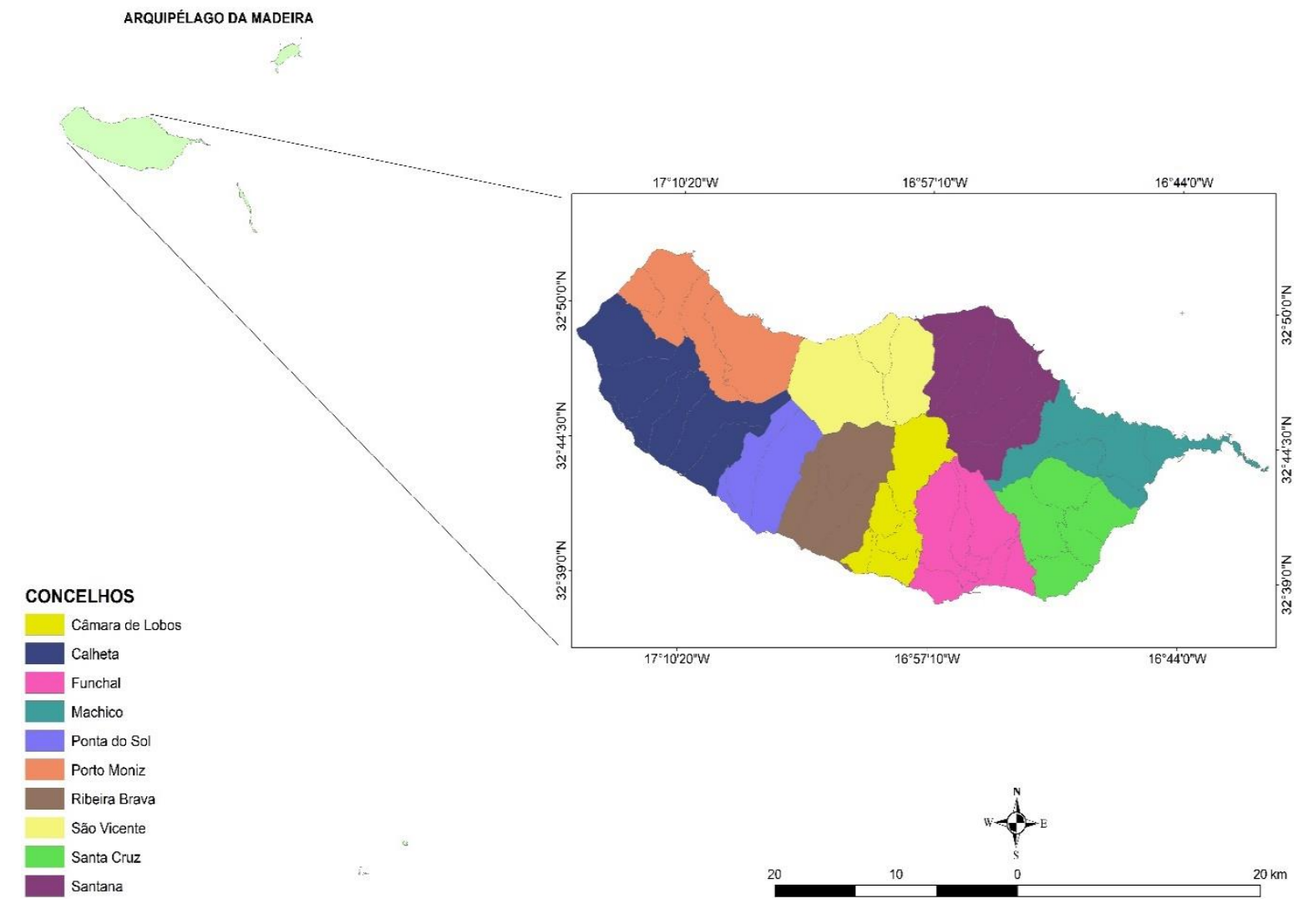

ARQUIPÉLAGO DA MADEIRA

Fonte - PRAM (2002).

Um conjunto de séries históricas de temperatura média mensal e do total mensal de precipitação para a Madeira foi utilizado no presente estudo, considerando a Normal Climatológica de 1961-1990. Os dados meteorológicos utilizados foram originados de 12 estações distribuídas por todo o Arquipélago (Tabela 1).

Tabela 1 - Estações meteorológicas utilizadas.

\begin{tabular}{cccc}
\hline NOME DA ESTAÇÃO & LAT(GRAUS) & LONG(GRAUS) & ALTITUDE (m) \\
\hline Porto Santo/Aeroporto(1) & 33,07 & $-16,35$ & 78 \\
Funchal/Observatório(1) & 32,65 & $-16,89$ & 58 \\
Sanatório do monte & 32,65 & $-16,90$ & 380 \\
Santa Catarina/Aeroporto & 32,69 & $-16,77$ & 58 \\
Lugar de Baixo/P. do Sol & 32,68 & $-17,09$ & 40 \\
Camacha & 32,66 & $-16,83$ & 680 \\
Bom sucesso & 32,65 & $-16,90$ & 290 \\
Chão do Areeiro & 32,72 & $-16,92$ & 1590 \\
Ponte delgada & 32,75 & $-16,71$ & 133 \\
Santana & 32,81 & $-16,89$ & 380 \\
Bica da Cana & 32,76 & $-17,06$ & 1560 \\
Santo da Serra & 32,73 & $-16,82$ & 660 \\
\hline
\end{tabular}

Fonte - Normais Climatológicas (1961-1990) (Maciel, 2005). 


\section{Espacialização da temperatura}

Esta etapa do processo de zoneamento foi calculada por meio de uma regressão linear múltipla (Equação 1), em que, se utilizou como variável dependente a temperatura média anual, e como variáveis independentes a latitude, a longitude e a altitude (Tabela 2) (VIANELLO e ALVES, 2004):

Temp $=\beta_{0}+\beta_{1} * Y+\beta_{2} * X+\beta_{3} * A L T$

em que:

Temp: temperatura do ar $\left({ }^{\circ} \mathrm{C}\right)$;

$\beta_{0}$ : constante de regressão;

Y: coordenada geográfica (latitude);

$X$ : coordenada geográfica (longitude);

ALT: altitude $(\mathrm{m})$;

$\beta_{1}, \beta_{2}, \beta_{3}$ : coeficiente de regressão para as variáveis $Y, X$ e ALT.

Tabela 2 - Constante e coeficientes de regressão para os meses de Janeiro a Dezembro.

\begin{tabular}{ccccc}
\hline \multirow{2}{*}{ Meses } & Constante de Regressão & \multicolumn{3}{c}{ Coeficientes de Regressão } \\
\cline { 3 - 5 } & & Latitude & Longitude & Altitude \\
\cline { 2 - 5 } & $\beta_{0}$ & $\beta_{1}$ & $\beta_{2}$ & $\beta_{3}$ \\
\hline Janeiro & 484,60 & $-13,5889$ & 1,237004 & $-0,00793$ \\
Fevereiro & 212,91 & $-5,66661$ & 0,628956 & $-0,00695$ \\
Março & 238,8 & $-6,04392$ & 1,41843 & $-0,00637$ \\
Abril & 127,07 & $-3,14735$ & 0,368154 & $-0,006$ \\
Maio & 118,39 & $-2,82974$ & 0,402142 & $-0,00554$ \\
Junho & 115,22 & $-2,62651$ & 0,505428 & $-0,00433$ \\
Julho & 157,93 & $-3,69643$ & 0,87302 & $-0,00349$ \\
Agosto & 152,37 & $-3,63257$ & 0,59291 & $-0,00372$ \\
Setembro & 78,35 & $-2,11853$ & $-0,84126$ & $-0,00621$ \\
Outubro & 167,32 & $-4,48101$ & $-0,1057$ & $-0,00696$ \\
Novembro & 240,38 & $-6,35015$ & 0,728525 & $-0,00722$ \\
Dezembro & 190,92 & $-5,10941$ & 0,299649 & $-0,00699$
\end{tabular}

Fonte - Organizado pelos autores (2019).

Após obtenção dos coeficientes de regressão, foi empregada uma álgebra de mapas, segundo a Equação 1, gerando logo a imagem matricial da temperatura média para o Arquipélago da Madeira. Os dados referentes a elevação do terreno, foram obtidos através de um Modelo Digital de Elevação.

\section{Balanço hídrico climatológico}

Após a obtenção dos dados de temperatura média do ar e da precipitação de todas as estações, calculou-se o balanço hídrico climático mensal, segundo o método proposto por Thornthwaite e

\begin{tabular}{llllll}
\hline Caminhos de Geografia & Uberlândia & v. 21, n. 73 & Mar/2020 & p. 296-306 & Página 299
\end{tabular}


Mather (1955), usando o programa "BHnorm", confeccionado em folha de EXCEL por Rolim et al. (1998). Por meio da folha de cálculo obteve-se a Deficiência Hídrica Anual (Dha), utilizando para tanto a capacidade de água disponível no solo, com o valor de referência de $100 \mathrm{~mm}$ (RICCE et al., 2014). Os resultados foram interpolados no software ArcGis 10.6 por meio do módulo de Spatial Analysis, com o interpolador Inverso da Distância Ponderada (IDW) gerando mapas de Dha. Nestes mapas foram estipuladas duas classes de risco para a cultura: Alto Risco: Dha > 100 mm e Baixo Risco: Dha $<100 \mathrm{~mm}$ (RICCE et al., 2014).

\section{RESULTADOS E DISCUSSÃO}

$\mathrm{Na}$ Figura 2 é possível observar o relevo da Madeira. As partes com cotas mais baixas situam-se ao redor da ilha tanto na costa Norte como na costa Sul. As regiões com cotas mais elevadas localizamse na parte central da llha. Na posse deste conhecimento partiu-se para a elaboração dos mapas de precipitação e temperatura.

Figura 2 - Mapa Hipsométrico da Madeira.

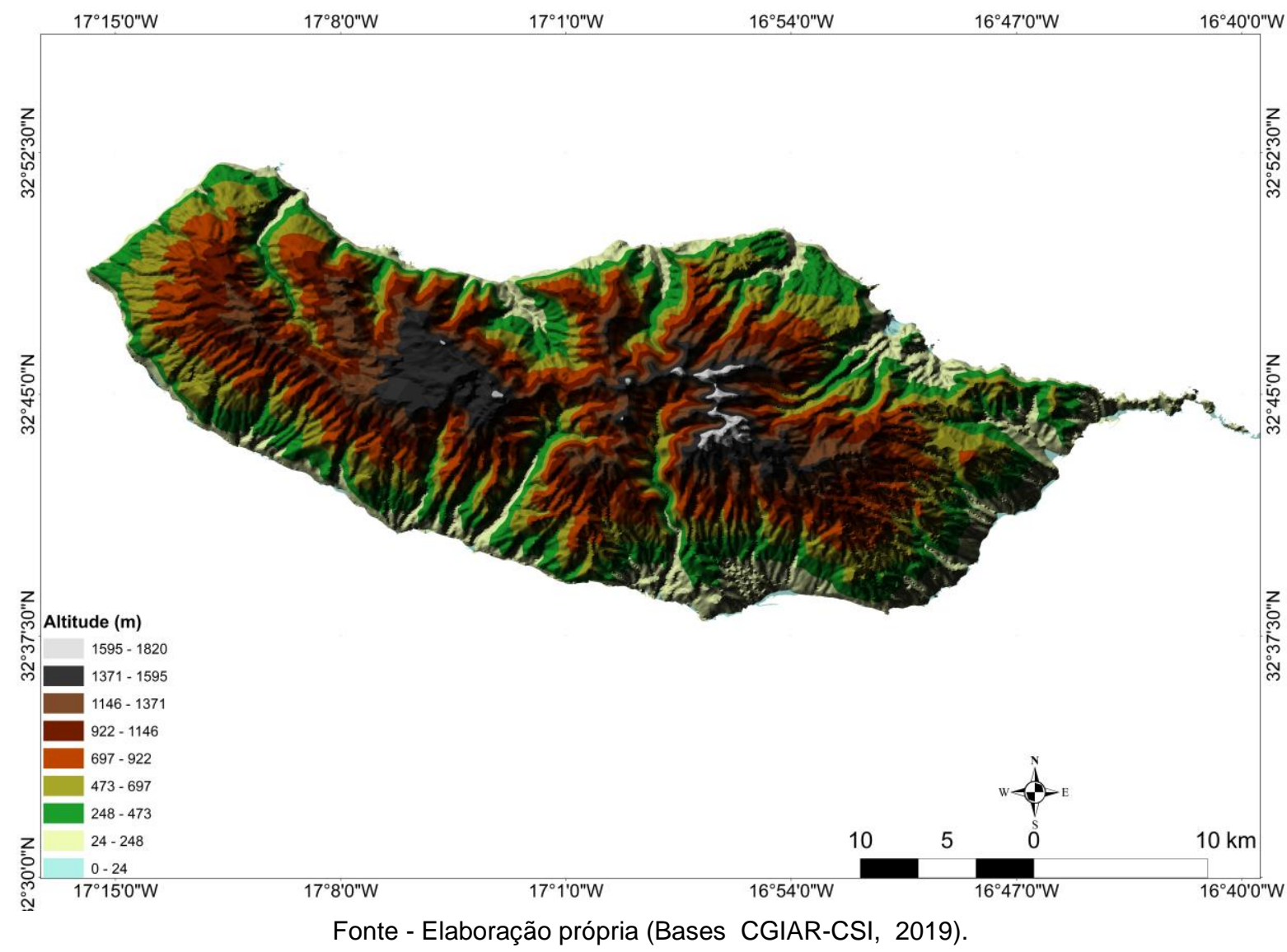

De maneira geral analisando as Figuras 3 e 4, verifica-se que nas partes mais elevadas da llha ocorrem os maiores volumes de precipitação. Os dados históricos das precipitações médias mensais demonstram que os maiores índices de precipitação ocorrem no outono/inverno, nos meses de Outubro até Março. Essas precipitações ocorridas nas llha apresentam uma dinâmica muito particular, em que, se verificam os maiores volumes na costa Norte e os menores na costa Sul (Figura 3). Nos pontos mais altos (Chão do Areeiro e Bica da Cana, a 1,590 e 1,560m, respectivamente) são obtidos os maiores volumes de precipitação médios mensais e anuais (Figura 4).

\begin{tabular}{llllll}
\hline Caminhos de Geografia $\quad$ Uberlândia & v. 21, n. 73 & Mar/2020 & p. 296-306 & Página 300
\end{tabular}


Figura 3 - Precipitações médias mensais.

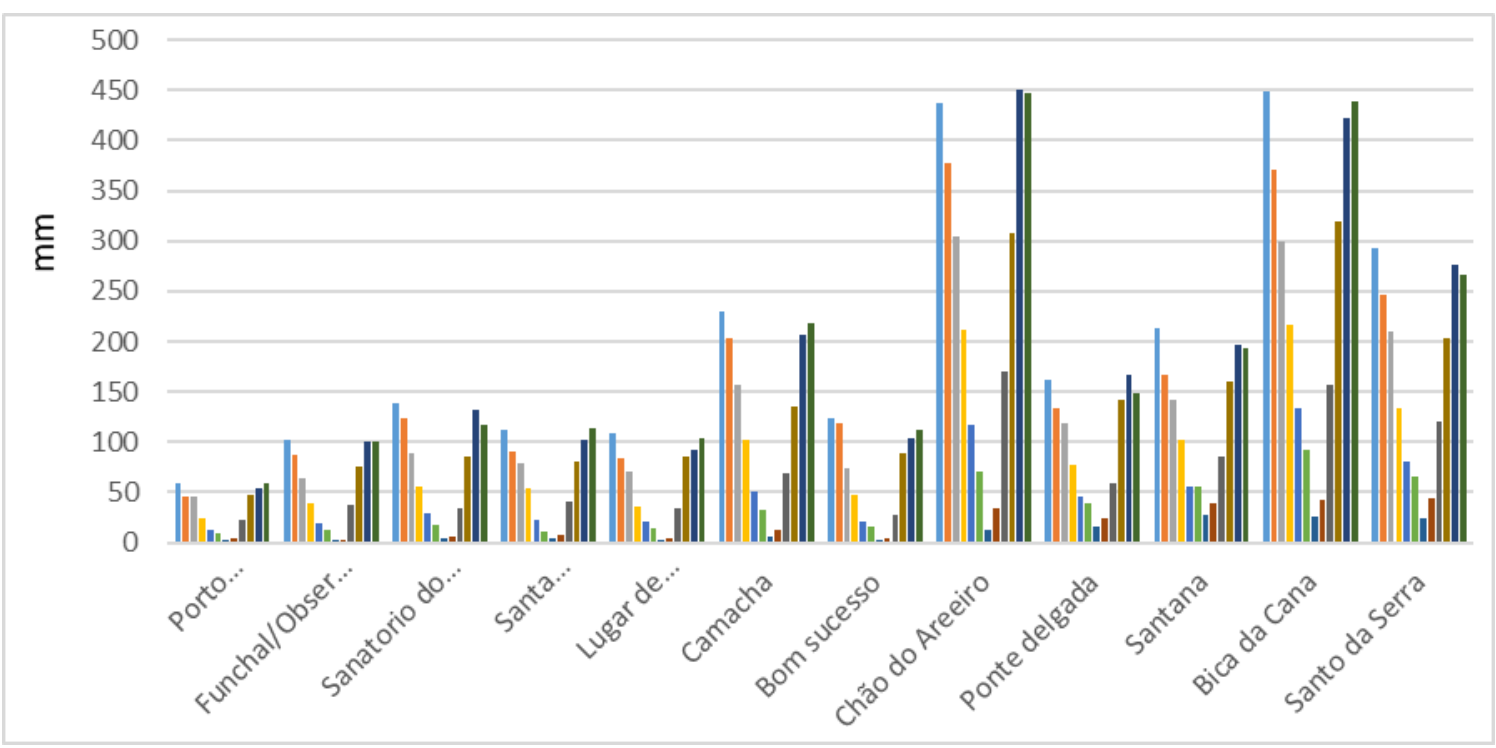

Fonte - Normais Climatológicas (1961-1990) (Maciel, 2005).

Figura 4 - Precipitação Média Anual.

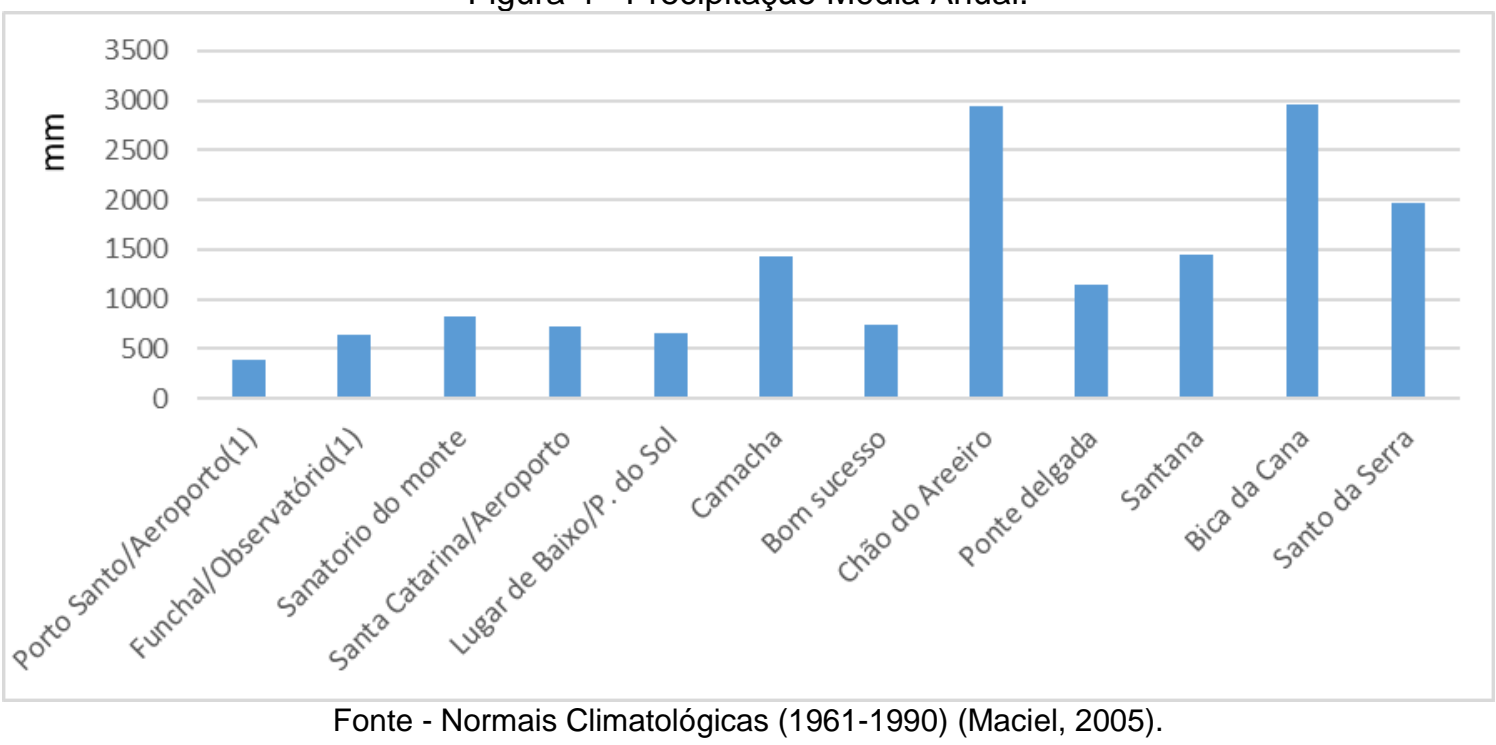

O mapa da distribuição das precipitações históricas da Madeira fornece informações fundamentais para o processo de seleção das culturas agrícolas que podem vir a ser instaladas, pois, com base nesse mapa é possível verificar se determinada cultura necessitará ou não de irrigação complementar. Duas premissas podem explicar os menores volumes de precipitação na costa Sul da Ilha. O primeiro refere-se às zonas mais urbanizadas da llha, em especial os municípios do Funchal e Ponta do Sol. O processo de urbanização associado ao relevo de menores altitudes, criaram condições para que essas áreas apresentassem as mais baixas precipitações. A segunda premissa, no entanto, salienta que a orientação Este-Oeste da ilha, com a exposição da costa Norte às correntes de ar mais frio e úmido e as cordilheiras centrais com elevada altitude demarcam o embate das nuvens contra as montanhas determinam a condensação do vapor de água, dando origem ao fenômeno da precipitação oculta, responsável pelo abastecimento dos lençóis freáticos (PRADA et al., 2009). Como resultado, o ar que chega à parte sul da ilha é mais seco, determinando uma menor precipitação.

A maior disponibilidade de recursos hídricos na costa Norte e nas partes mais elevadas do terreno resulta do efeito sumativo da orientação e exposição da ilha e do fenômeno de condensação originam maiores volumes de precipitação. Esta maior disponibilidade de recursos hídricos no Norte foi aproveitado, desde o início do povoamento da Madeira, com a canalização e transporte da água para

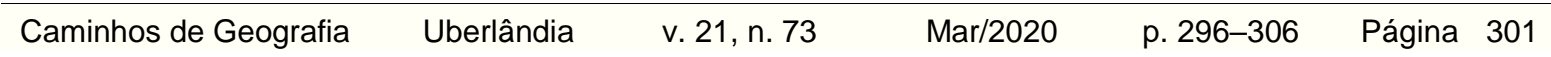


- Sul da ilha. Este transporte é realizado em canais construídos pelos agricultores e são designados por "levadas", que tem como função principal o transporte gravitacional da água do Norte para o Sul, sendo canais construídos entre e através das montanhas. A modelação dos dados permitiu constatar a llha como um sistema único apresenta precipitações que são satisfatórias para a maioria dos cultivos agrícolas (Figura 5).

Figura 5 - Mapa das precipitações médias anuais da Madeira.

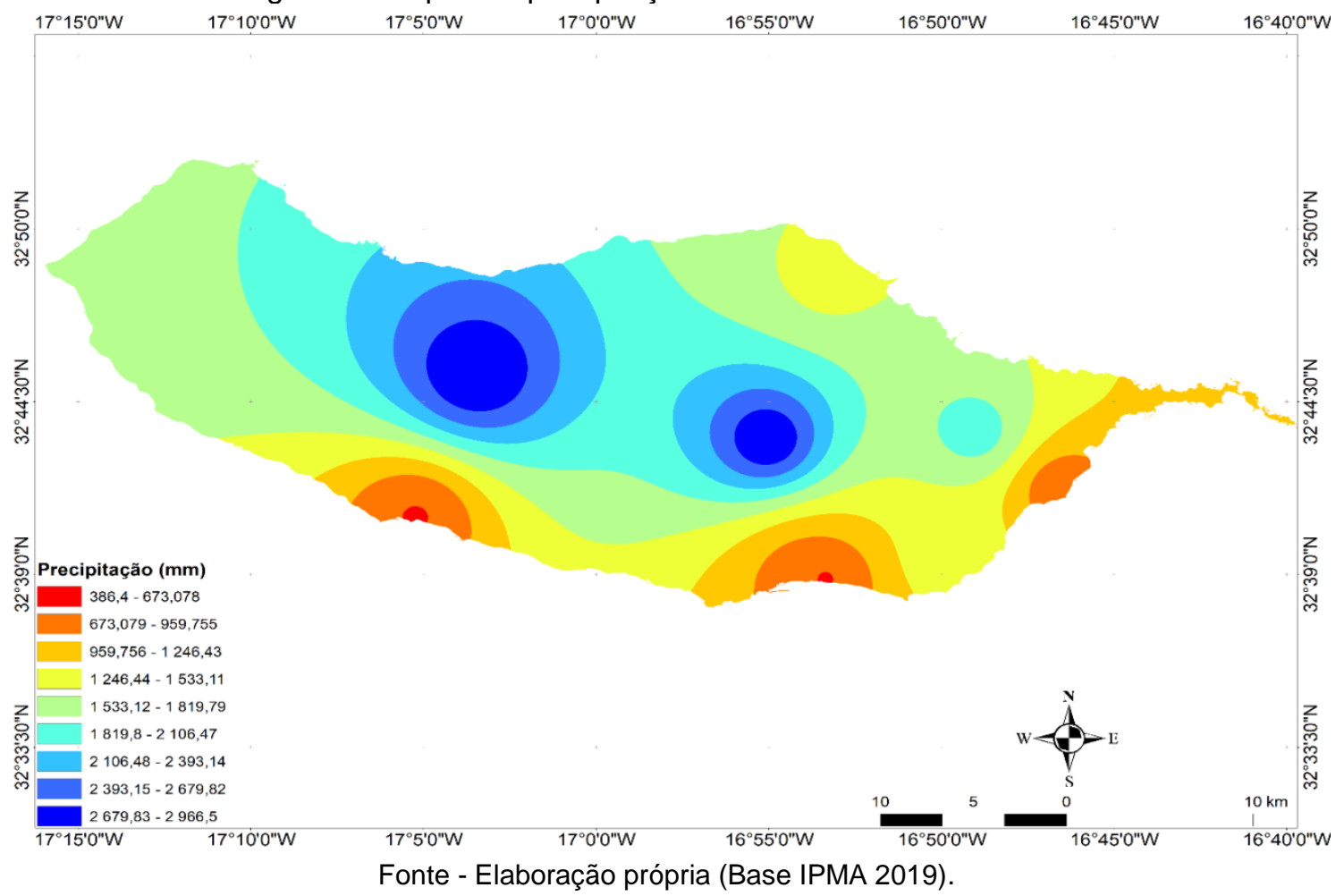

No entanto, para a seleção de culturas aptas ao desenvolvimento não basta apenas o conhecimento referente aos índices e localização das maiores e menores taxas de precipitação; é necessário também confrontá-las com informações sobre o clima, em especial no que diz respeito à temperatura e às amplitudes térmicas que ocorrem em toda a llha (Figura 6). De maneira semelhante aos dados referentes com a precipitação para a llha os dados de temperatura mais baixas são obtidos nas estações com maior altitude e concentrando-se mais no inverno.

Figura 6 - Temperaturas médias mensais.

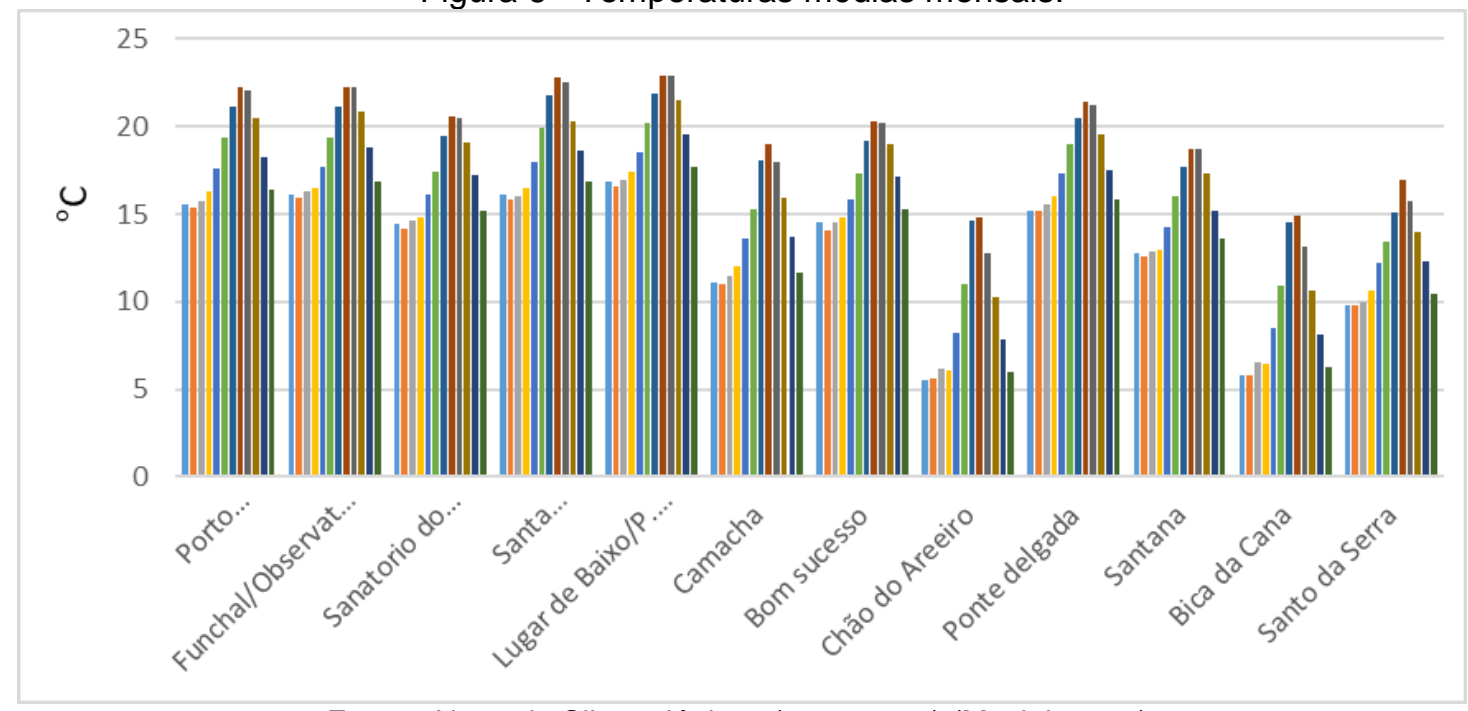

Fonte - Normais Climatológicas (1961-1990) (Maciel, 2005).

$\begin{array}{lllll}\text { Caminhos de Geografia } & \text { Uberlândia } & \text { v. 21, n. 73 } & \text { Mar/2020 } & \text { p. 296-306 }\end{array}$ Página 302 
A utilização dos dados históricos das temperaturas médias anuais, através da sua interpolação permitiu obter o mapa de temperatura da llha (Figura 7). Nesse mapa observa-se que, quanto maior a altitude do terreno, menor é a temperatura registada, sendo o inverso também verdadeiro. A temperatura decresce em média $0,8 \stackrel{\circ}{\circ}$ graus por cada $100 \mathrm{~m}$ de altitude. $\mathrm{Na}$ orla costeira de toda Ilha (Norte, Sul, Leste e Oeste) observam-se as temperaturas médias mais elevadas $\left(20,2{ }^{\circ} \mathrm{C}\right)$. A associação da temperatura com o relevo apresenta ainda certos "canais" que correspondem aos vales profundos entre as montanhas, onde se observa um microclima com temperaturas mais elevadas, à semelhança de toda orla costeira Figura 7. As temperaturas médias mínimas $\left(6,88^{\circ} \mathrm{C}\right)$ observadas na llha, localizam-se nas partes mais elevadas do território nas partes centrais da Madeira. De acordo com Fritzsons et al. (2008) existe a correlação diretamente inversa entre a elevação do relevo e a diminuição da temperatura, e que se torna evidente quando observamos a figura 6 .

Figura 7 - Temperatura média anual da Madeira.

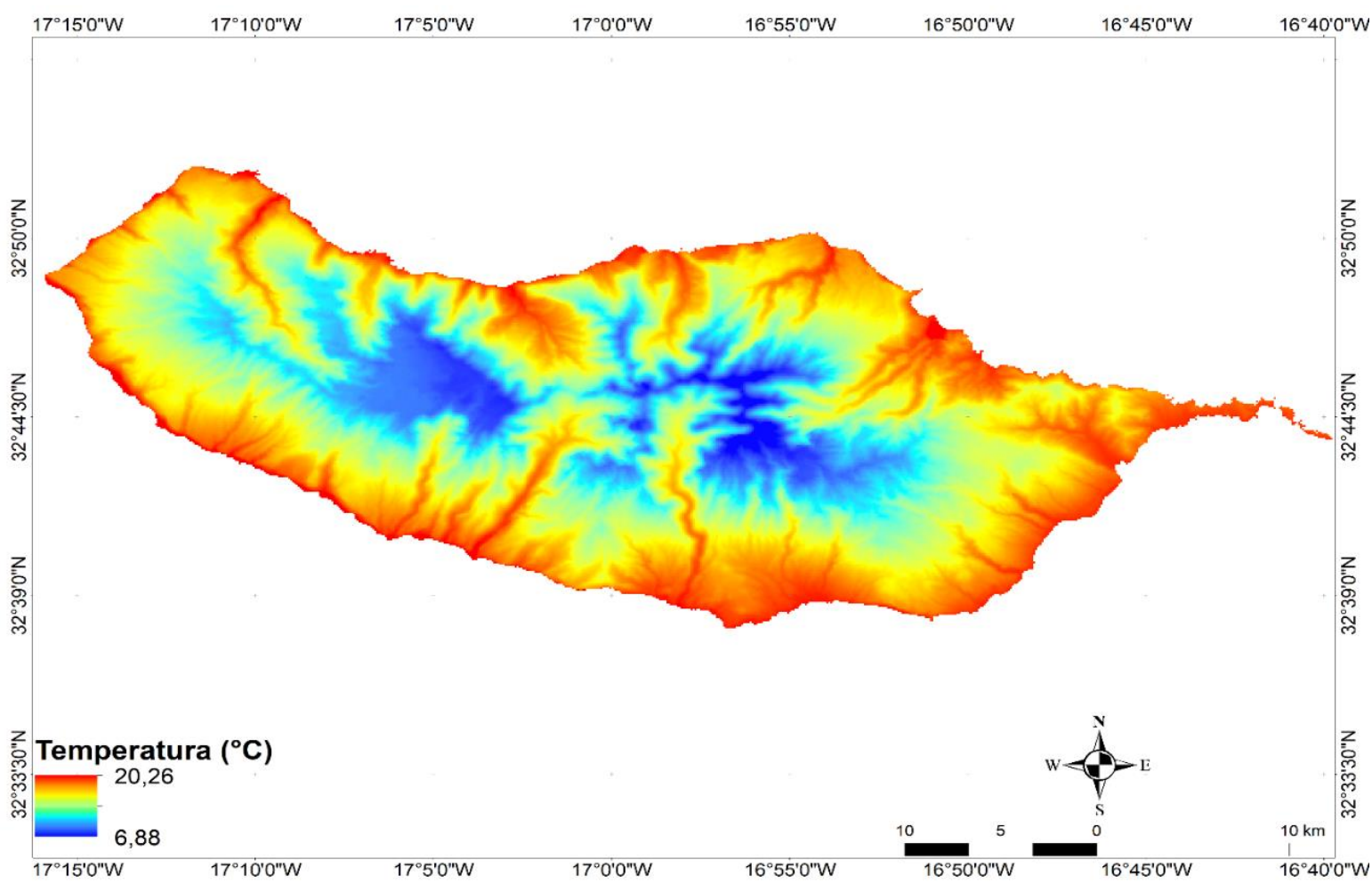

Fonte - Elaboração própria (Bases IPMA, 2019).

Após a elaboração do balanço hídrico climatológicos, juntamente com os cruzamentos dos mapas de temperatura, buscou-se então, determinar quais seriam as zonas mais propícias para o cultivo da videira na Madeira. Nesta determinação teve-se em consideração, de acordo com Jones (2007) a temperatura crítica para a cultura $\left(<12^{\circ} \mathrm{C}\right)$, e temperatura aceitável para a cultura $\left(12-22^{\circ} \mathrm{C}\right)$. Temperaturas muito elevadas podem propiciam a degradação do ácido málico, diminuindo a acidez da baga (RIZZON e SGANZERLA, 2007). No entanto de acordo com a série histórica das temperaturas para a Madeira esses valores dificilmente são atingidos nas atuais condições climáticas. Após o cruzamento destes mapas, originou-se o Zoneamento Agroclimático da cultura da videira para a Madeira (Figura 8). Quatro classes foram definidas após o cruzamento de dados em que: 1 é a zona apta com irrigação complementar; corresponde a $299.89 \mathrm{~km}^{2}$ e $40,48 \%$ da área agrícola total (Tabela 3). Nesta classe as temperaturas são as ideais para o desenvolvimento da cultura da vinha, no entanto verifica-se um certo deficit hídrico, existindo a necessidade de suplementação hídrica via irrigação. A segunda zona propícia para o desenvolvimento da vinha na ilha apresenta um excesso hídrico; de maneira similar com a primeira classe, esta área apresenta também as temperaturas ideais para o desenvolvimento da cultura, porém apresenta um excesso de água proveniente de chuvas e nevoeiros muito comuns na região Norte da llha. O cultivo da videira pode ser realizado, porém o aparecimento de doenças fúngicas provenientes da umidade é mais comum nessa área em comparação com a classe 1 .

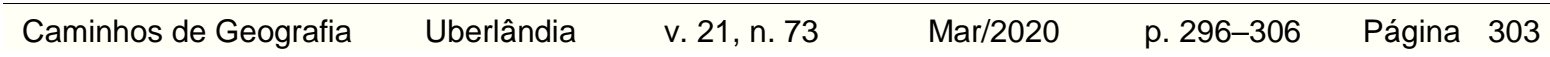


Tabela 3 - Classes de zoneamento agroclimático da videira para a Madeira.

\begin{tabular}{ccc}
\hline Classes & Área $\left.\mathbf{( k m}^{2}\right)$ & Área (\%) \\
\hline Apta com irrigação Complementar & 299,89 & 40,48 \\
Excesso Hídrico & 137,61 & 18,58 \\
Inapta por Carência Térmica & 30,67 & 4,14 \\
Inapta por Carência Térmica e Restrição Hídrica & 15,5 & 2,10 \\
Rede Natura 2000 & 257,03 & 34,70 \\
\hline Fonte - Organizado pelos autores (2019).
\end{tabular}

Figura 8 - Zoneamento agroclimático da videira para a Madeira.

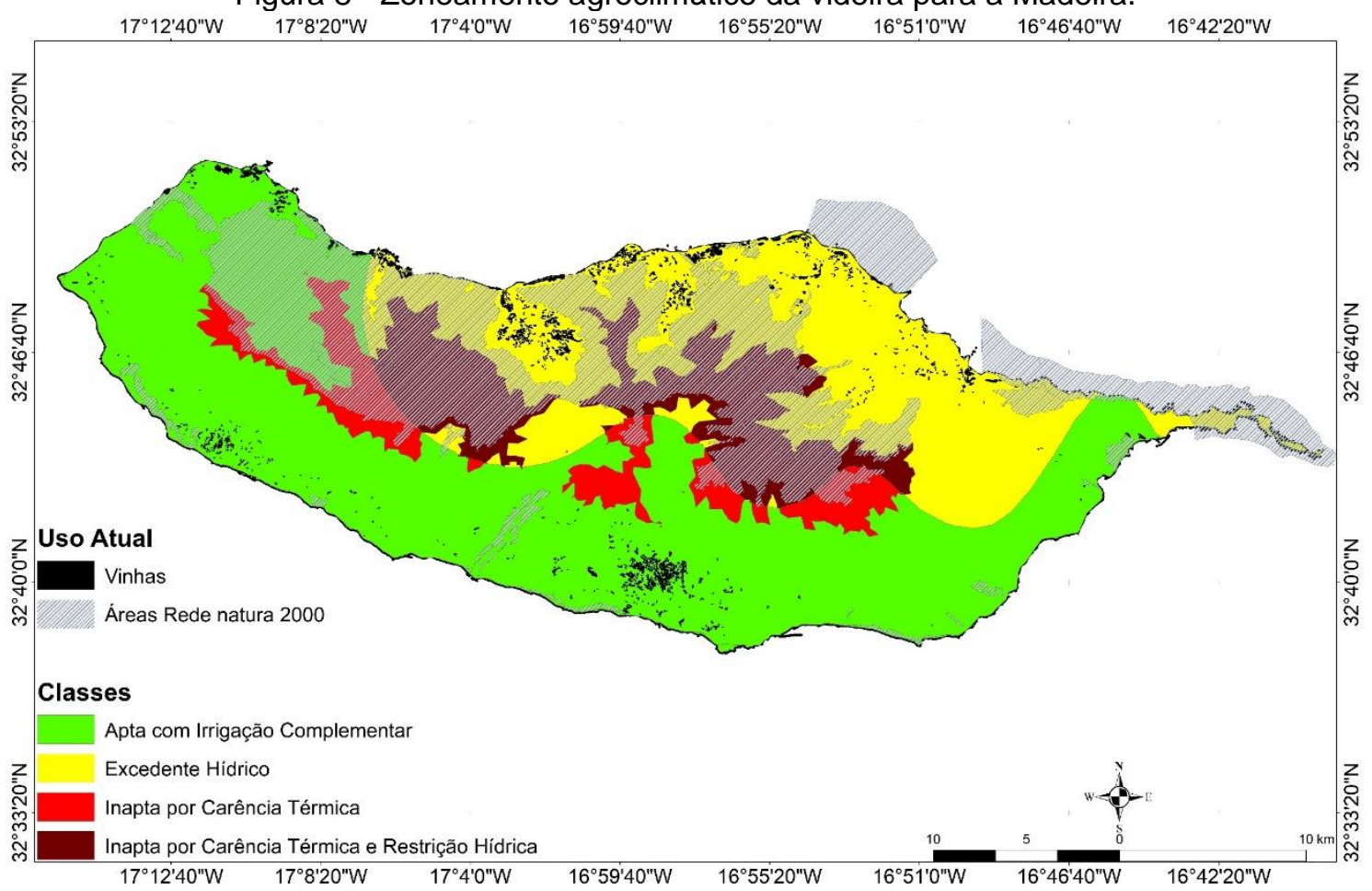

Fonte - Elaboração própria (Bases DROTA, 2018 e IPMA, 2019).

A terceira classe definida nesse estudo foi classificada como zona inapta por carência térmica; essa classe apresenta ao longo do ano temperatura muito baixas para o desenvolvimento satisfatório da videira, não alcançando na maior parte dos meses temperaturas acima dos $12{ }^{\circ} \mathrm{C}$. Por fim a $4^{\mathrm{a}}$ a classe foi classificada como inapta por apresentar Carência Térmica e Restrição Hídrica é a zona em que existe a associação de temperaturas muito baixas além de excesso hídrico ao longo de todo o ano, fatores esses que tornam inapto o desenvolvimento da cultura da videira.

Um

ponto muito importante que deve ser salientado é a presença do Parque Natural da Madeira localizado na parte Norte da llha (Figura 7). Essas áreas foram apresentadas no mapa de zoneamento apenas de maneira ilustrativa, visto que, as mesmas não podem ser trabalhadas para o desenvolvimento da cultura da vinha.

Com o mapa gerado (Figura 7), associou-se ao mesmo as atuais áreas com a cultura da videira na Ilha da Madeira (pontos com coloração preta); verificando com isso que a classificação realizada se deu de maneira muito satisfatória, visto que, os pontos localizam-se nas áreas com coloração verde e amarela (aptas para a cultura).

\section{CONSIDERAÇÕES FINAIS}

Com os resultados obtidos no presente estudo, será possível que tanto os produtores, como os investigadores e decisores políticos possam realizar uma melhor tomada de decisão para implantação de novos plantios de videira na llha da Madeira. Visto que, o zoneamento realizado permitirá sinalizar as áreas com maior adequabilidade para o desenvolvimento da cultura, segundo os fatores hídrico e térmico, adequado ás exigências da cultura.

\begin{tabular}{llllll}
\hline Caminhos de Geografia & Uberlândia & v. 21, n. 73 & Mar/2020 & p. 296-306 & Página 304
\end{tabular}


Para o cultivo da videira na llha da Madeira, todo litoral Sul da llha, assim como boa parte do Norte, são áreas propicias para o desenvolvimento da cultura; no entanto no litoral sul, irrigação complementar é necessária para satisfazer as necessidades hídricas da cultura. Já no litoral Norte é necessário ter alguns cuidados com possível aparecimento de doenças fúngicas, devido aos grandes volumes de precipitação e de neblinas presentes na área.

\section{AGRADECIMENTOS}

Agradecemos ao o Instituto de Desenvolvimento Regional (IDR), pelo financiamento imprescindível da atividade do BG ISOPlexis, através do Programa Operacional Madeira 14-20, operação CASBio, ref. a M1420-01-0145-FEDER-000011.

DROTA (Direção Regional do Ordenamento do Território e Ambiente). Informação Geográfica cedida pela Direção Regional do Ordenamento do Território e Ambiente.

\section{Referências}

CGIAR-CSI (Consultative Group for International Agricultural Research-Consortium for Spatial Information). Disponível em: http://www.cgiar-csi.org/data. Acesso em março 2019.

CRUZ, M. J.; AGUIAR, R., CORREIA, A.; TAVARES, T.; PEREIRA, J.S.; SANTOS, F.D. Impacts of climate change on the terrestrial ecosystems of Madeira. International Journal of Design \& Nature and Ecodynamics, v.4, № 4, p. 413-422, 2009. https://doi.org/10.2495/DNE-V4-N4-413-422

DREM. (Direção Regional de Estatística da Madeira). Estatísticas da Agricultura e Pesca da Região Autónoma da Madeira 2014, DREM, Funchal 70 p, 2015.

DROTA (Direção Regional do Ordenamento do Território e Ambiente). Cartas de Solos e de Ocupação do Solo da RAM. Acesso em março de 2019.

FRITZSONS, E.; AGUIAR, A. V.; MANTOVANI, L. E. Relação entre altitude e temperatura: Uma contribuição ao zoneamento climático no Estado do Paraná. REA - Revista de estudos ambientais, v.10, n.1, p. 49-64, 2008.

IPMA (Instituto Português do Mar e da Atmosfera). Disponível em: http://www.ipma.pt/pt/publicacoes/boletins.jsp?cmbDep=cli\&cmbTema=pcl\&idDep=cli\&idTema=pcl\&cu rAno=-1. Acesso em março 2019.

JONES, G. V. Climate Change and the global wine industry. Proceedings from the 13th Autralian Wine Industry Technical Conference, 2007, Adelaide, Austrália.

MACIEL, O. Precipitações Intensas na Ilha da Madeira, Incidências, Contrastes Espaciais e Causas Sinópticas, Faculdade de Letras da Universidade de Coimbra, 2005.

MEDEIROS, R. M.; AZEVEDO, P. V.; SABOYA, L. M. F.; FRANCISCO, P. R. M. Classificação climática e zoneamento agroclimático para o município de Amarante- PI. Revista Brasileira de Agricultura Irrigada, v.7, n.2, p.170-180, 2013. https://doi.org/10.7127/rbai.v7n200011

MORAES, S. L. de. Variabilidade climática e sua influência na produtividade da cultura da batata em Ponta Grossa, PR. 74 f. Monografia (Geografia) - Universidade de São Paulo. São Paulo.

PRADA, S.; MENEZES de SEQUEIRA, M.; FIGUEIRA, C.; OLIVEIRA da SILVA, M. Fog precipitation and rainfall interception in the natural forests of Madeira Island (Portugal), Agricultural and Forest Meteorology, n. 149, p.1179-1187, 2009. https://doi.org/10.1016/j.agrformet.2009.02.010

PRAM (Plano Regional da Água da Madeira), Funchal: Secretaria Regional do Ambiente e Recursos Naturais. 328p 2002.

RICCE, W. S.; CARVALHO, S. L. C. de; CARAMORI, P. H.; ROBERTO, S. R. Zoneamento agroclimático da cultura da videira no Estado do Paraná. Semina: Ciências Agrárias, v.35, n.4, 2014. https://doi.org/10.5433/1679-0359.2014v35n4Suplp2327

RIZZON, L. A., SGANZERLA, V. M. A. Ácidos tartárico e málico no mosto de uva em Bento Gonçalves-RS. Ciência Rural, v.37, n.3, p.911-914, 2007. https://doi.org/10.1590/S0103$\underline{84782007000300053}$

\begin{tabular}{lllll}
\hline Caminhos de Geografia & Uberlândia & v. 21, n. 73 & Mar/2020 & p. 296-306 Página 305
\end{tabular}


ROLIM, G. S; SENTELHAS, P. C; BARBIERI, V. Planilhas no ambiente EXCEL para os cálculos de balanços hídricos: normal, sequencial, de cultura e de produtividade real e potencial. Revista Brasileira de Agrometeorologia, v.6, p.133-137, 1998.

SILVA, R. C. A. Agricultura Biológica na llha da Madeira: constrangimentos e potencialidades. 2013. 126 f. Dissertação (Mestrado em Gestão do Território Ambiente) - Universidade Nova de Lisboa. Lisboa.

SOARES, J. M.; COSTA, F. F. Irrigação. In: SOARES, J. M.; LEÃO, P. C. S. (Ed.). A vitivinicultura no semiárido brasileiro. Brasília: Embrapa Informação Tecnológica, 2009.

THORNTHWAITE, C. W.; MATHER, J. R. The Water Balance: publications in climatology. New Jersey Drexel Institute of Technology, 1955.

TONIETTO, J.; MANDELLI, F.; ZANUS, M. C.; GUERRA, C. C.; PEREIRA, G. E. O clima vitícola das regiões produtoras de uvas para vinhos finos do Brasil. IN: TONIETTO, J.; RUIZ, V. S.; GÓMEZMIGUEL, V. D. eds. Clima, zonificatión y tipicidad del vino en regiones vitivinícolas iberoamericanas. 2012, Madrid: CYTED, p.113-145.

VIANELLO, R. L.; ALVES, A. R. Meteorologia básica e aplicações. Viçosa: Universidade Federal de Viçosa, 2004.

Recebido em: 19/06/2019

Aceito para publicação em: 20/01/2019 